\title{
Maternal Knowledge of Stunting in Rural Indonesia
}

\author{
Cougar Hall ${ }^{1}{ }^{*}$, Cudjoe Bennett ${ }^{2}$, Benjamin Crookston ${ }^{1}$, Kirk Dearden ${ }^{2}$, Muhamad Hasan ${ }^{2}$, \\ Mary Linehan ${ }^{2}$, Ahmad Syafiq $^{3}$, Scott Torres ${ }^{2}$ and Joshua West ${ }^{1}$
}

${ }^{1}$ Brigham Young University, USA

${ }^{2}$ IMA World Health, USA

${ }^{3}$ Universitas Indonesia, Indonesia

\begin{abstract}
Child undernutrition and stunting remain serious public health problems in Indonesia. According to the Health Belief Model, increasing mothers' knowledge of stunting is fundamental to establishing accurate threat perceptions predictive of behavior change. The purpose of this study was to increase understanding of factors related to maternal knowledge of stunting in Indonesia by addressing three questions: 1) How familiar with stunting are Indonesian mothers? 2) What antecedent factors do Indonesian mothers associate with stunting? and 3) What health effects do Indonesian mothers associate with stunting? A total of 3,150 mothers participated in structured face-to-face interviews. Study measures targeted four main variables. Mothers were asked: 1) Have you heard of stunting?; 2) Have you heard of shortness?; 3) What causes stunting/shortness?; and 4) What are the effects of stunting? Only 66 (2.1\%) mothers reported having heard of, read about, or knew something about stunting. Approximately two-thirds of participants attributed stunting to hereditary factors. Interrupted growth $(33.7 \%)$, idiocy $(13.8 \%)$, and easy to get sick $(11.8 \%)$ were identified as health effects of stunting. Results highlight the need for health promotion and education efforts focused on increasing basic knowledge of stunting, its causes, and its health effects among Indonesian mothers.
\end{abstract}

Keywords: Stunting, knowledge, childhood nutrition, Indonesia, Health Belief Model.

\section{INTRODUCTION}

Stunted growth, or stunting, is defined as a heightfor-age $Z$ score more than two standard deviations below the World Health Organization (WHO) child growth standards for age and sex. Stunting increases the risk of child disease and deaths [1], adversely affects cognitive and motor development [2], lowers performance at school [3], increases the risk of overnutrition and non-communicable diseases [4], and reduces productivity in adulthood [5]. Stunting is the result of chronic or persistent undernutrition stemming from poor maternal nutrition, poor feeding practices, and poor sanitation [3,4]. An estimated 156 million children under five years of age worldwide are stunted [6].

Despite dramatic economic advances in the last two decades, child undernutrition and stunting remain serious public health problems in Indonesia. Of the 24.5 million children under 5 years of age in Indonesia, approximately 9.2 million (37\%) are stunted [7]. Regions with large rural populations exceed the national average, including West Kalimantan (39.7\%), Central Kalimantan (39.6\%) and South Sumatra $(38.9 \%) .8$ The high stunting rate in Indonesia is associated with a combination of complex factors, including nutrition, hygiene and childcare practices

*Address correspondence to this author at the Department of Public Health, Brigham Young University, 2140 LSB, Provo, Utah, 84602, USA; Tel/Fax: 801-422-5656; E-mail: cougar_hall@byu.edu characterized by poor dietary diversity and sub-optimal feeding practices, low maternal and paternal education inadequate maternal nutrition, shorter maternal height, lower per-head household expenditure, low birthweight, insufficient birth spacing, low levels of exclusive breastfeeding, open defecation and insufficient hygiene practices, and household food insecurity $[7,9,10]$.

Improving mothers' behavioral beliefs, behaviors, and education are key to addressing stunting. Improved maternal education, especially, has consistently been associated with reductions in child stunting [11]. This complex relationship between education and stunting is likely mediated by other, more proximal factors. For example, Semba et al. [9] note that mothers in Indonesia are generally the primary caregivers for children and that maternal education is associated with protective behaviors including increased visits to the local health post or posyandu, access and use of closed latrines, receipt of childhood immunizations, and receipt of vitamin A capsules. These parental protective caregiving behaviors reflect a mother's knowledge of, and ability to implement, practices supportive of child growth and development.

The Health Belief Model (HBM) is a value expectancy theory postulating that an individual's desire to avoid illness or to get well (value) and one's belief that a specific health action available would prevent or ameliorate illness (expectancy) is predictive 
of health behavior change. Key constructs of the HBM include perceived susceptibility, or an individual's subjective perception of his or her risk of contracting a health condition, and perceived severity, an individual's opinion of how serious a condition and its symptoms or health consequences are [12]. The combination of perceived severity and perceived susceptibility equate to an individual's perceived threat. In other words, the individual's perception that action or inaction is a threat to health [12]. The HBM theorizes that for behavior change to occur, individuals must feel threatened by their current behavioral patterns and the subsequent expected outcomes. The HBM also includes the constructs of perceived benefits and perceived barriers which also impact health behavior change efforts. Perceived benefits highlight what can be expected, typically the positive effects, of a specific action [12]. Perceived barriers refer to the tangible and psychological costs of changing or modifying an existing behavior. Accuracy in perceiving both benefits and barriers to health behavior change requires the gaining of new knowledge or factual information as well as the correcting of existing misinformation [12]. In effect, the accuracy of threat perceptions, as well as perceived benefits and barriers, are largely dependent on an individual's knowledge of a specific health condition, the condition's causal factors, and finally, the condition's probable effects or health outcomes. Based upon the HBM, assessing mothers' knowledge and understanding of stunting is fundamental to establishing accurate threat perceptions predictive of health behavior change. The purpose of this study was to increase understanding of factors related to maternal knowledge of stunting in Indonesia. In particular, this study aimed to address the following research questions: 1) How familiar with stunting are Indonesian mothers? 2) What antecedent factors do Indonesian mothers associate with stunting? and 3) What health effects do Indonesian mothers associate with stunting?

\section{METHODS}

\section{Design}

Data for this study comes from formative research gathered to inform the design and implementation of a National Nutrition Communications Campaign (NNCC) targeting 10 provinces (West and East Java, West and East Nusa Tenggara, Gorontalo, Maluku, North Sulawesi, West and Central Kalimantan, and South Sumatra) across the Indonesian archipelago. This formative research represents a collaborative effort between IMA World Health (IMA), the University of
Indonesia's Center for Nutrition and Health Studies, and the Ministry of Health in Indonesia. Data was gathered from mid-September to mid-October, 2014. A quantitative survey was conducted in seven provinces and 10 districts, with site selections made to ensure coverage of the varied cultures and religions within the provinces.

\section{Sample}

The study sample consisted of pregnant mothers and mothers of children under two years of age. Specific regions were selected for the larger effort because of the high prevalence of stunting, representativeness and accessibility. The number of respondents within each region was determined using the World Health Organization's 30 Cluster Method [13]. A village within a district was considered a cluster, and 30 were selected from each district. Respondents within clusters were then randomly selected to participate. The sample for the current study included 3,150 respondents.

\section{Procedure}

Participants were recruited to participate in structured interview. After a participant's home was randomly selected for participation, an interviewer traveled to the home, acquired consent to participate and then conducted a face-to-face interview. Participation rate was $100 \%$. Interviewers used a structured guide to ask questions and collect responses. Participants' responses were recorded on the actual interview guide and were then transferred to an electronic database for data cleaning and analyses.

\section{Measurement}

Interviewers collected data from participating mothers regarding demographics, stunting knowledge and other key variables related to nutritional practices. Demographic variables related to socioeconomic status were assessed by a single measure of familial wealth used to represent home-based assets. This variable was created by summing respondents' reports that they owned any of the following assets (yes/no): radio, cell phone, refrigerator, television, bicycle/boat, motorcycle/ motorbike, and computer/laptop. These variables resulted in a Cronbach's Alpha coefficient of .60. The summed total was then divided by seven (the total number of possible assets) to create a ratio. Knowledge of stunting was measured using four variables. First, mothers were asked if they had heard of stunting (yes/no). Mothers that reported 'yes' were 
then asked to identify signs and symptoms of stunting, which included height corresponding to age (yes/no), shorter than average (yes/no), dwarf (yes/no), and did not know (yes/no). Mothers were asked if they had ever heard of shortness (i.e., the condition of shortness) (yes/no). Mothers that reported 'yes' were then asked to identify signs and symptoms of shortness, which included height does not correspond to age (yes/no), shorter than average (yes/no), dwarf (yes/no), and did not know (yes/no). Two items were used to measure knowledge of factors known to cause stunting/shortness. First, mothers were asked what causes stunting/shortness. Response options included undernourished (yes/no), gets sick often (yes/no), lack of activity (yes/no), and inherited (yes/no). Next, they were asked what it takes to avoid stunting/shortness. Response options included take vitamins (yes/no), eat a lot (yes/no), do sports (yes/no), and keep hygiene (yes/no). Lastly, a single item was used to measure mothers' knowledge of the effects of stunting. Mothers were asked what they thought stunting/shortness in children under 2 years of age would cause. Response options included idiocy (yes/no), easy to get sick (yes/no), interrupted growth (yes/no), and nothing (yes/no).

\section{Analysis}

Stata SE version 15.0 was used to conduct all analyses. Frequency statistics were calculated to summarize demographic variables and to identify sources of stunting-related knowledge. Due to skip patterns in the questionnaire, sample sizes vary according to analyses as not all participants answered every potential questionnaire item.

\section{RESULTS}

This study sample included 3,150 pregnant mothers $(33.3 \%)$ and mothers of children under two years of age $(66.7 \%)$ (Table 1). The average age of mothers was 27.8 years. The highest level of education attained for the majority of mothers was graduating from elementary school $(42.4 \%)$, followed by graduating from secondary high $(26.1 \%)$, junior high $(24.3 \%)$, and college $(7.2 \%)$.

The term stunting was generally not known by participants in this study. Of the 3,150 participants, only $66(2.1 \%)$ (Table 2) reported having heard of, read about, or knew something about stunting. Among mothers familiar with the term stunting, 33.3\% associated the term with dwarf, $22.7 \%$ with height does not correspond to age, and $19.7 \%$ with shorter than average. Approximately $12 \%$ of those mothers indicating they had heard of or read about the term stunting, indicated they did not know what the term meant. Respondents were much more familiar with the term and condition of shortness. Exactly one-third $(33.3 \%)$ of participants indicated they had heard of, read about, or knew something about shortness. Approximately half $(50.3 \%)$ of respondents associated shortness with the term dwarf, $25.0 \%$ associated shortness with shorter than average, and $14.5 \%$ associated shortness with height does not correspond to age.

Participants who had heard or, read about, or knew something about stunting $(\mathrm{n}=66)$ or shortness $(\mathrm{n}=$ 1,052) answered two questions related to the antecedents of stunting. The first: In your opinion, what causes stunting/shortness in children under two years of age? Hereditary factors (inherited) were mentioned by $68.0 \%$ (Table 3 ) of respondents as a cause of stunting/shortness, with lack of food intake (undernourished) next at $38.9 \%$, followed by illness (gets sick often) at $8.7 \%$, and lack of activity at $7.7 \%$. Participants also answered the question: In your opinion, what does it take to avoid stunting/shortness in

Table 1: Sample Characteristics, $n=3,150$

\begin{tabular}{|c|c|c|c|}
\hline Variable & & $\mathbf{n}$ & $\mathbf{n}$ \\
\hline \hline \multirow{2}{*}{ Highest level of education } & Some elementary or elementary graduate & 42.35 & 1,334 \\
\cline { 2 - 4 } & Some junior high or junior high graduate & 24.32 & 766 \\
\cline { 2 - 4 } & Some high school or high school graduate & 26.13 & 823 \\
\cline { 2 - 4 } & Some college or college graduate & 3.21 & 227 \\
\hline Mother status & Pregnant & 66.67 & 2,100 \\
\cline { 2 - 4 } & Child $<2$ & Mean & SD \\
\hline Age & & 27.75 & 7.08 \\
\hline Assets & & 3.86 & $1.59(0-7)$ \\
\hline
\end{tabular}


Table 2: Knowledge of Stunting/Shortness, $n=3,150$

\begin{tabular}{|c|c|c|c|}
\hline Variable & & $\%$ & $\mathbf{N}$ \\
\hline \multirow{2}{*}{$\begin{array}{c}\text { Have you ever heard/read/know about } \\
\text { stunting? }\end{array}$} & Yes & 2.10 & 66 \\
\hline & No & 97.90 & 3,084 \\
\hline \multirow[t]{5}{*}{ What is stunting? } & Height does not correspond to the child's age & 22.73 & 15 \\
\hline & Shorter than average & 19.70 & 13 \\
\hline & Dwarf & 33.33 & 22 \\
\hline & Other & 12.12 & 8 \\
\hline & Do not know & 12.12 & 8 \\
\hline \multirow{2}{*}{$\begin{array}{c}\text { Have you ever heard/read/know about } \\
\text { shortness? }\end{array}$} & Yes & 33.30 & 1,052 \\
\hline & No & 66.60 & 2,098 \\
\hline \multirow[t]{5}{*}{ What is shortness? } & Height does not correspond to the child's age & 14.54 & 153 \\
\hline & Shorter than average & 25.00 & 263 \\
\hline & Dwarf & 50.29 & 529 \\
\hline & Other & 6.08 & 64 \\
\hline & Do not know & 4.09 & 43 \\
\hline
\end{tabular}

Table 3: Knowledge of Factors known to Cause Stunting/Shortness, $n=1,052$

\begin{tabular}{|c|c|c|c|}
\hline Variable & & $\%$ & $\mathbf{N}$ \\
\hline \multirow[t]{4}{*}{ In your opinion, what causes stunting/shortness in children under $2 \mathrm{y} / \mathrm{o} ?$} & Undernourished & 38.88 & 409 \\
\hline & Gets sick often & 8.65 & 91 \\
\hline & Lack of activity & 7.70 & 81 \\
\hline & Inherited & 67.97 & 715 \\
\hline \multirow{4}{*}{$\begin{array}{l}\text { In your opinion, what does it take to avoid stunting/shortness in children under } 2 \\
y / 0 ?\end{array}$} & Take vitamins & 47.53 & 499 \\
\hline & Eat a lot & 51.43 & 541 \\
\hline & Do sports & 33.17 & 349 \\
\hline & Keep hygiene & 9.70 & 102 \\
\hline
\end{tabular}

children under two years of age? Eat a lot (51.4\%), take vitamins (47.5\%), and do sports (33.2\%), were the most common responses followed by keep hygiene $(9.7 \%)$.

A total of 669 participants answered the question: In your opinion, stunting/shortness in children under two years old will cause what? The most frequently indicated response was interrupted growth (33.7\%) (Table 4), followed by idiocy (13.8\%), easy to get sick $(11.8 \%)$, and nothing $(4.4 \%)$

\section{DISCUSSION}

Stunting, or height-for-age below standard, is an important undernutrition indicator among children under

Table 4: Knowledge of what Stunting/Shortness Causes, $n=669$

\begin{tabular}{|c|c|c|c|}
\hline Variable & & $\%$ & $\mathbf{N}$ \\
\hline \multirow[t]{4}{*}{ In your opinion, stunting/shortness in children under $2 \mathrm{y} / \mathrm{o}$ will cause what? } & Idiocy & 13.78 & 145 \\
\hline & Easy to get sick & 11.79 & 124 \\
\hline & Interrupted growth & 33.65 & 354 \\
\hline & Nothing & 4.37 & 46 \\
\hline
\end{tabular}


five. As a signatory to the global movements Scaling Up Nutrition (SUN), the Millennium Development Goals and the Sustainable Development Goals, decreasing stunting rates in Indonesia is a public health priority [10]. The purpose of this study was to gain an understanding of factors related to maternal knowledge of stunting in Indonesia to inform stunting prevention efforts. Perhaps this study's most important finding is that two-thirds of respondents, a total of 2,098 mothers, had never heard of, read about, or knew something about stunting or shortness. This widespread lack of knowledge and awareness presents a serious challenge to modifying stunting-related behaviors. While knowledge alone is rarely a sufficient catalyst for behavior change, it is key to improving one's perceptions of both susceptibility and severity, important constructs in the HBM predictive of taking action [12]. It should be noted that one challenge to stunting-prevention efforts in Indonesia is that a word for stunting simply does not exist in Bahasa Indonesian. In the absence of stunting-specific vocabulary, approximately one-third of respondents in this study identified stunting with shortness, an equivalent term and condition among many Indonesians. However, less than $15 \%$ of those respondents correctly identified shortness as being low height-for-age. These results demonstrate a strong need for both establishing stunting-specific vocabulary or terminology and engaging in a country-wide communication effort to inform and educate Indonesian mothers about this condition.

The results of this study's first research question help to emphasize the importance of its second question aimed at understanding antecedent factors Indonesian mothers associate with stunting. Among those mothers who were aware of stunting or shortness, the majority considered this condition to be a direct result of heredity. This misunderstanding may be partially explained by noting that respondents in this study associated the terms stunting and shortness with dwarf (cebol) and midget (kerdil). The cognitive coupling of stunting with genetic mutations affecting the skeletal system only further complicates education and prevention efforts. However, this finding is consistent with research in other areas of the world where individuals consistently associate stunting with genetics rather than prolonged undernutrition [14]. According to the HBM, falsely attributing a short stature to genetics creates a substantial perceived barrier to behavior change. Often narrowly defined as simply the costs associated with a particular behavior, perceived barriers include an individual's belief that an outcome expectation is beyond his or her control [12]. Much like Social Cognitive Theory's self-efficacy construct [15] and the Theory of Planned Behavior's perceived behavioral control construct [16], perceived barriers are powerful predictors of behavior. These constructs address the belief that one can take effective action to reduce the personal or familial risk of an undesired outcome expectation. Perceived barriers are especially forceful in preventing or undermining behavior change efforts when an individual perceives that taking action will be ineffective in altering the outcome. Even when an individual's perception of susceptibility, severity, and subsequent threat are accurate, believing the outcome to be beyond one's control creates a substantial barrier to change as otherwise potential courses of preventative action are considered futile. Important to this study and according to the HBM, mothers who consider the cause of stunting to be hereditary, and thus beyond their control, may be unlikely to engage in preventative behaviors. The dearth of knowledge about stunting identified among this study sample, together with confusion regarding the antecedents of stunting, represent two significant barriers to stunting prevention efforts in Indonesia.

The current study sought to identify the health effects Indonesian mothers associate with stunting. Effects of stunting have been well documented and include reduced long-term and successive physical and cognitive growth, compromised immune response and strength, and reduced life expectancy. Familiarity with the consequences of stunting, whether cognitive, financial, physical, or otherwise, are essential to accurately perceiving severity of, and subsequent perceptions of threat imposed by, stunting. Few mothers in this study sample identified the effect that stunting has on cognition, immune response, and longterm physical growth. Again, drawing upon constructs in the HBM, perceived severity forms part of the perceived threat to one's health. Associating negative outcomes with stunting may cause a mother to feel that her child's health is threatened, thereby motivating corrective action.

\section{RECOMMENDATIONS}

Efforts to prevent stunting are ongoing across Indonesia. Current programs designed and implemented by both government and non-government entities to directly prevent childhood stunting appropriately target key health behaviors, optimal infant and young child feeding practices, and services, such 
as: exclusive breastfeeding until six months, appropriate complementary feeding, improving dietary diversity, distribution of multivitamins including iron and folic acid, distribution of micronutrient supplements for children, deworming medicine for children, medical treatment for under-nourished children, fortification of food with micronutrients such as vitamin A, iron, and iodine, as well as prevention and treatment of malaria for pregnant women and children. Additionally, important efforts are currently being made in addressing indirect causes of undernutrition, such as the environment, lack of access to quality health services, and food security challenges in the households. Other ongoing and vital supportive efforts effective in preventing stunting include the promotion of handwashing, increasing access to clean water, maternal instruction related to psychosocial stimulation for babies and children, family planning information, creation of local nutrition gardens and fisheries. Each of these efforts reflect best practices related to maternal and child health generally, and stunting prevention specifically, and should be continued and expanded, particularly targeting rural and poor populations. The results of this study highlight, however, the continued need for intensified health promotion and education efforts focused on increasing basic knowledge and understanding related to stunting, its causes, and its health effects among Indonesian mothers, fathers and other care-givers. These elementary, yet foundational efforts, are instrumental in creating the accurate perceptions and beliefs needed to enhance the efficacy of all other programs and energies and to appropriately motivate mothers and fathers to action. The findings of this study help to establish a continued need to increase knowledge of stunting, its antecedents, and related health effects among Indonesian mothers.

\section{Limitations}

The current study has several key limitations. The absence of stunting-specific vocabulary, while certainly a challenge for stunting-prevention efforts, is also a significant limitation to this study. It is possible that portions of the low knowledge and understanding of stunting among Indonesian mothers presented here is attributed to lexical semantics given the array of closely related terms mothers associate with short stature. Data analyzed in this study was part of a large-scale formative assessment of population demographics, maternal nutritional knowledge, infant and young childhood feeding practices, as well as household and community resources. The survey questionnaire and interview guide was not created specifically to address this study's research questions. While the data and analysis herein are adequate in addressing these questions, future research specifically aimed at understanding maternal knowledge of stunting, its antecedents, and health effects of Indonesian mothers may be beneficial. While a strength of the current study is its large sample size, future investigations might employ more qualitative methodologies such as focus groups, observation, in-depth interviews, or an entirely open-ended interview format and focus group discussions to enlarge and deepen the understanding of stunting-related knowledge among Indonesian mothers.

\section{CONCLUSION}

Stunting knowledge, and subsequent perceptions of susceptibility and severity to this condition, are nearly nonexistent among Indonesian mothers. Among mothers who are aware of stunting, the majority perceive it to be a condition of genetics or heredity and not associated with suboptimal future cognitive attainment, health and productivity. This general lack of knowledge about stunting and misunderstanding related to the antecedents of stunting combine to create significant challenges to behavior change and efforts to prevent stunting in Indonesia. Public health programs designed to address stunting among Indonesian mothers should begin with education efforts aimed at increasing stunting-related knowledge and creating accurate perceptions of this condition's threat to health and wellbeing. Such efforts should likewise include focus on specific causal factors or antecedents of stunting, as well as both short- and long-term health effects of stunting.

\section{ACKNOWLEDGEMENTS}

This study was made possible by IMA-World Health, and supported by funding through MCA-Indonesia.

\section{REFERENCES}

[1] Black RE, Allen LH, Bhutta ZA, Caulfield LE, de Onis M, Ezzati M, et al. Maternal and child undernutrition: global and regional exposures and health consequences. Lancet 2008; 371: 243-260. https://doi.org/10.1016/S0140-6736(07)61690-0

[2] Crookston BT, Dearden KA, Alder S, Porucznik C, Stanford $\mathrm{J}$, Merrill $\mathrm{R}$, et al. Impact of early and concurrent stunting on cognition. Matern Child Nutr 2011; 7: 397-409. https://doi.org/10.1111/j.1740-8709.2010.00255.x

[3] Victora CG, Adair L, Fall C, Hallal PC, Martorell R, Richter L, et al. Maternal and child undernutrition: consequences for adult health and human capital. Lancet 2008; 371: 340-357. https://doi.org/10.1016/S0140-6736(07)61692-4 
[4] Black RE, Victora CG, Walker SP, Bhutta ZA, Christian P, de Onis $\mathrm{M}$, et al. Maternal and child undernutrition and overweight in low-income and middle-income countries. Lancet 2013. 382: 427-451. https://doi.org/10.1016/S0140-6736(13)60937-X

[5] Alderman H, Hoddinott J, Kinsey B. Long term consequences of early childhood malnutrition. Oxf Econ Pap 2006; 58: 450-474. https://doi.org/10.1093/oep/gpl008

[6] World Health Organization. Joint child malnutrition estimates - Levels and trends in child malnutrition: Key findings of the 2016 edition. Available from: http://www.who.int/nutgrowthdb/ estimates2016/en/

[7] Rachmi CN, Agho KE, Li M, Baur LA. Stunting, underweight and overweight in children aged 2.0-4.9 years in Indonesia: Prevalence trends and associated risk factors. PLoS ONE 2016; 11(5): e0154756. https://doi.org/10.1371/journal.pone.0154756

[8] Kementerian Kesehatan RI. Rencana Strategis Kementerian Kesehatan Tahun 2010-2014. Jakarta. Available from: http://www.depkes.go.id/index.php/berita/pressrelease/1055-bersama-kita-berantas-malaria.html

[9] Semba RD, de Pee S, Sun K, Sari M, Akhter N. Bloem MW. Effect of parental formal education on risk of child stunting in Indonesia and Bangladesh: A cross-sectional study. Lancet 2008; 371: 322-328 https://doi.org/10.1016/S0140-6736(08)60169-5

[10] Torlesse H, Cronin AA, Sebayang SK, Nandy R. Determinants of stunting in Indonesian children: Evidence from a cross-sectional survey indicate a prominent role for the water, sanitation and hygiene sector in stunting reduction. BMC Public Health 2016; 16: 669. https://doi.org/10.1186/s12889-016-3339-8

[11] Schott W, Crookston BT, Lundeen EA, Stein AD, Behrman JR. The young lives determinants and consequences of child growth project team. Child growth from ages 1 to 5 and 5 to 8 years in Ethiopia, India, Peru and Vietnam: Key distal household and community factors. Soc Sci Med 2013; 97: $278 \mathrm{e} 287$.

[12] Rosenstock IM. The health belief model: Explaining health behavior through expectancies. In Glanz K, Lewis FM, Rimer BK (Eds.), The Jossey-Bass health series. Health Behavior and Health Education: Theory, Research, and Practice (pp. 39-62). Jossey-Bass: San Francisco 1990.

[13] Hoshaw-Woodard S. Description and comparison of the methods of cluster sampling and lot quality assurance sampling to assess immunization coverage. World Health Organization. 2001. Available from: www.who.int/vaccinesdocuments/

[14] Gibson RS. Principles of Nutritional Assessment. 2nd ed. Oxford university press: New York 2005.

[15] Bandura A., Social Foundations of Thought and Action: A Social Cognitive Theory. Prentice-Hall: Englewood Cliffs, New Jersey 1986.

[16] Ajzen I. The theory of planned behavior. Organ Behav Hum Decis Process 1991; 50(2): 179-211. https://doi.org/10.1016/0749-5978(91)90020-T

https://doi.org/10.6000/1929-4247.2018.07.04.2

(c) 2018 Hall et al.; Licensee Lifescience Global.

This is an open access article licensed under the terms of the Creative Commons Attribution Non-Commercial License (http://creativecommons.org/licenses/by-nc/3.0/) which permits unrestricted, non-commercial use, distribution and reproduction in any medium, provided the work is properly cited. 